\title{
Pulmoner embolide gözden kaçan semptomlar: Vertigo ve senkop
}

\author{
Unnoticed symptoms of pulmonary embolism: Vertigo and syncope \\ Hacı Mehmet Çalışkan, Şevki Hakan Eren*, Ali Taner, Erol Tülümen, Hüseyin \\ Murat Demirbaş, Şeyhmuz Kaya
}

Acil Servis Kliniği (Dr. H. M. Çalışkan), Kardiyoloji Kliniği (Dr. A. Taner, Dr. E. Tülümen), Göğüs Hastalıkları Kliniği (Dr. H. M. Demirbaş), Yozgat Devlet Hastanesi, TR-66200 Yozgat, Acil Tıp Anabilim Dalı (Doç. Dr. Ş. H. Eren), Cumhuriyet Üniversitesi Tıp Fakültesi, TR-58140 Sivas, Acil Servis Kliniği (Dr. Ş. Kaya), Eskişehir Devlet Hastanesi, TR-26060 Eskişehir

\section{Özet}

Pulmoner emboli (PE) acil servis'lerde sık karşılaşılan, zor tanı konulan ve mortalitesi oldukça yüksek pulmoner acillerden biridir. Pulmoner emboli vakaları acil servislere çok farklı klinik bulgularla gelebilir. En sık karşılaşılan semptomları ani başlayan dispne, plöretik göğüs ağrısı, öksürük, hemoptizi, taşipne ve taşikardidir. Senkop, pulmoner emboli olgularında nadir görülen ilk başvuru sebebi olmasına rağmen özellikle masif pulmoner emboli vakalarında daha sık gözlenmektedir ve acilen tanı konulup tedavi edilmediği takdirde mortalitesi çok yüksektir. Bu nedenle acil servise senkop ile başvuran hastaların ayırıcı tanısında pulmoner emboli mutlaka akılda bulundurulmalıdır. Bu çalışmada senkop ve vertigo şikayetleri ile acil servise başvuran, ya da hastane içerisinde ani hipotansiyon ve senkop geçiren beş masif pulmoner emboli olgusu sunuldu.

Anahtar sözcükler: Pulmoner emboli, vertigo, senkop

\begin{abstract}
Pulmonary embolism (PE) is one of the pulmonary emergent disease which hardly diagnosed, high mortality rates, and frequently seen in emergency department. PE cases are seen many different clinical symptoms. Most common symptoms are sudden started dyspnea, pleuritic chest pain, coughing, hemoptysis, tachypnea, and tachycardia. Syncope is rarely first referring symptom of the PE cases, however, in massif PE cases syncope is more frequently seem and unless urgent diagnosis and treatment, mortality rates is quite high. Therefore, in differential diagnosis of the syncope patients PE must keep in mind. In this study, five massive PE cases were presented who admitted to emergency service with syncope and vertigo symptoms.
\end{abstract}

Keywords: Pulmonary embolism, vertigo, syncope

Geliş tarihi/Received: 10 Şubat 2014; Kabul tarihi/Accepted: 30 Haziran 2014

\section{*İletişim adresi:}

Dr. Şevki Hakan Eren, Acil Tıp Anabilim Dalı, Cumhuriyet Üniversitesi Hastanesi. TR-58140

Sivas. E-posta: shakaneren@hotmail.com 


\section{Giriş}

Pulmoner emboli(PE), acil servislere çok farklı klinik tablolarla gelebilen, zor tanı konulan mortalitesi yüksek bir hastalıktır. Pulmoner embolinin klinik tablosunun birçok hastalığ 1 taklit etmesi ve bazen de nonspesifik semptomlara yol açması, tanısının zor konulmasının en büyük nedenidir. Hastanın acil servise başvurduğu dönemde, PE tanısının konulamaması, mortaliteyi 5 kat arttırmaktadır [1, 2]. Özellikle masif PE olan hastalar senkopla acil servise gelebilirler ve masif pulmoner emboliye bağlı hastane dışında senkop atağı geçiren ve başvuru sırasında bilinci yerinde olan hastalarda PE tanısı siklıkla atlanabilmektedir [3]. Biz bu serimizde masif PE'si olup istirahatte iken vertigo dışında belirgin şikayetleri olmayan, ayağa kalktıklarında kısa süreli nöbet ve ardından senkop geçirerek acil servise başvuran (dört olgu), ve ayağa kalkmakla ani hipotansiyon ve ardından kısa süreli senkop atağı geçiren bir olgu olmak üzere toplam beş masif PE olgusunu sunduk.

\section{Olgu sunumları}

\section{Olgu 1}

Kırk bir yaşında bayan hasta bulantı, kusma, baş dönmesi, yürüyememe şikayetleri ile acil servise başvurdu. Hasta son 15 gün içerisinde iki defa gögüs ve sırt ağrısı ile acil servise başvurduğu başka bir hastanede herhangi bir patoloji bulunamadığı, son başvurduğu gün ise özellikle şiddetli vertigo atağ1 olduğu ve evde ayağa kalkınca senkop geçirme öyküsü ile ambulans çağırdıklarını belirtti. acil serviste takibi esnasında vertigosunun azaldığını ifade eden hasta, hasta yakınları tarafından ayağa kaldırıldığında kısa süreli senkop geçirdi. Fizik muayenesinde bilateral solunum sesleri doğal, nabız 112/dk, TA: 110/70 mmHg olup ek ses veya üfürüm duyulmadı. Batın muayenesi doğaldı. Dört extremite nabızları alınıyordu. Nörolojik muayenesinde her iki göz de lateral nistagmus olup her iki extremitenin motor fonksiyonu eşitti ve patolojik refleks yoktu. Hastanın son dört yıldır oral kontraseptif kullandığı öğrenildi.

Senkop geçiren ve vertigosu olan hastanın nörolojik muayenesi vertigonun, periferik vertigo ya da hipotansif nedenli olabileceğini düşündürdü. Senkop esnasında kan basıncı $70 / 50 \mathrm{mmHg}$ olarak ölçüldü. Hastada sinüs taşikardisi vardı. Ortostatik hipotansiyon semptomları ve takiben senkobu olan hastada kardiyoloji uzmanı ile konsülte edilerek transtorasik ekokardiyografi yapıldı. Ekokardiyografide sağ atrium, sağ ventrikül ve pulmoner arterde genişleme, sağ atrium içinde $38 \times 12 \mathrm{~mm}$ çapında hareketli trombüs izlendi. Hastaya toraks BT angiografi çekildi ve her iki ana pulmoner arterde yaygın tromboemboli tesbit edildi.

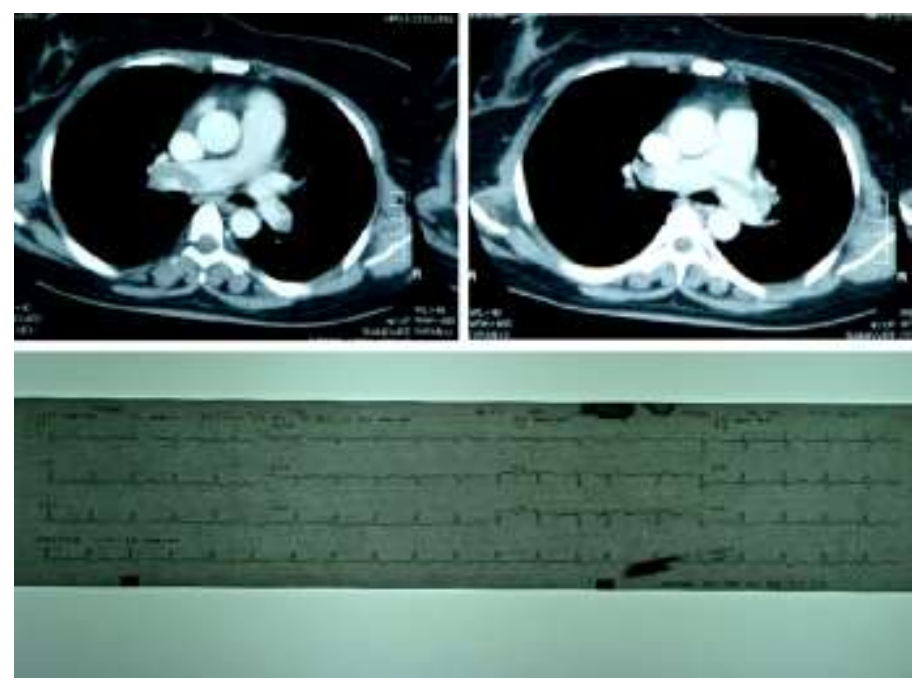

Resim 1. Birinci olguya ait BT anjiyo ve EKG. 


\section{Olgu 2}

Otuz dört yaşında kadın hasta evde baş dönmesi ve bayılma şikayetleri ile acil servise getirildi. acil servise başvurusunda hastanın bilinci konfüze ve gözler sola deviye idi. Öyküsünden 15 gün önce sağ bacağında şişlik ve ağrı olduğu, bir hafta önce bu şikayetinin geçtiği ancak son bir haftadır halsizliğinin ve uzun süredir de göğüs ortasında hafif bir ağrısının olduğu öğrenildi. Belirgin dispne şikayeti olmayan hasta son bir haftadır eforla birlikte çarpıntısının olduğunu ve halsizliğinin arttığını ifade etti. Sigara ve alkol kullanmayan hasta 3 çocuk annesi olup son doğumunu 8 yıl önce gerçekleştirmişti. Hasta acil servise başvurduğunda kan basınc1 140/80 mmHg, nabız 114/dakika, solunum sayısı 22/dakika, alınan kan gazında oksijen satürasyonu (Sat $\left.\mathrm{O}_{2}\right) \% 85 \mathrm{PCO}_{2} 31,2 \mathrm{mmHg}$ ölçüldü (oda havasında). Hasta monitörize edilip 4 lt/dakikadan oksijen tedavisi başlandi. Bilateral solunum sesleri doğal olan hastada ek ses ya da üfürüm duyulmadı. Rutin laboratuar testleri(tam kan sayımı ve acil biyokimya) normal sinırlarda saptandı.

Konfüze olması ve senkop geçirmesi nedeni ile hastaya kraniyal tomografi çekildi ve normal olarak değerlendirildi. Hasta acil serviste yakınları tarafindan ayağa kaldırıldığında tekrar kısa süreli senkop geçirdi. Senkop esnasında hastanın kan basıncı $80 / 55 \mathrm{mmHg}$ olarak ölçüldü. Hastanın ani hipotansiyon ve senkop geçirmesi, EKG'sinde $\mathrm{V} 1$, V2, V3 derivasyonlarında $1 \mathrm{~mm}$ ST depresyonu, $\mathrm{T}$ negatifliği olması, $\mathrm{O}_{2}$ satürasyonun \%85 olmas1 nedeni ile PE ön tanısıla kardiyoloji konsültasyonu ile ekokardiyografi yapıldı. Ekokardiyografide sağ atrium ve sağ ventrikül geniş, pulmoner arter basıncı (PAB) $45 \mathrm{mmHg}$, interventriküler septumda sol ventriküle doğru sıçrayıcı hareket mevcuttu. Sağ ventrikül apex'i dışında hipokinetikti. Toraks BT angiografisinde her iki pulmoner arterde ve segmenter dallarında tromboemboli olduğu saptandı. Hastaya trombolitik tedavi uygulandı. Bir haftalık takip sonrasında şifa ile taburcu edildi. Daha sonra hastaya poliklinik kontrollerinde Faktör V leiden eksikliği tanısı konulmuştur.

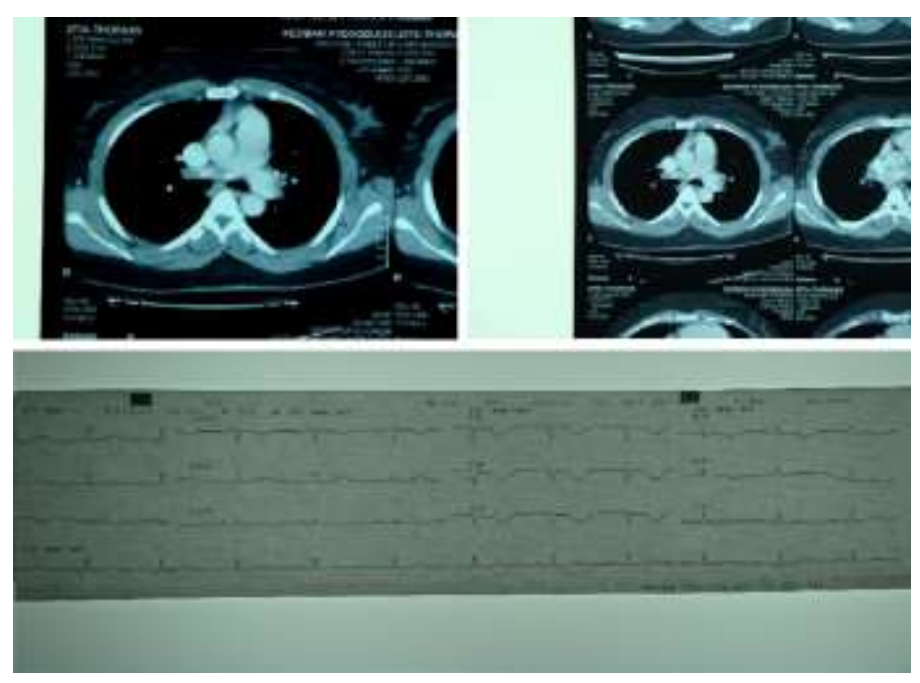

Resim 2. İkinci olguya ait BT anjiografi ve EKG.

\section{olgu 3}

Altmış yedi yaşında bayan hasta acil servise senkop nedeni ile getirildi. acil servise geldiğinde bilinci konfüze TA: $100 / 60 \mathrm{mmHg}$, solunum sayıs $28 / \mathrm{dk}$ ve $\mathrm{Sat}_{2} \mathrm{O}_{2}$ : \%85 olarak ölçüldü, hastaneye başvurusundan kısa bir süre sonra hastanın jeneralize kasılması oldu ve TA 80/60 mmHg ölçüldü. Hastaya yapılan ekokardiyografide; sağ boşluklarının dilate olduğu gözlendi. Hasta BT angiografi çekimi ardından kardiyopulmoner arrest gelişti. Hasta pulmoner emboliye bağlı kardiyojenik şok nedeni ile arrest olduğu saptandı. 

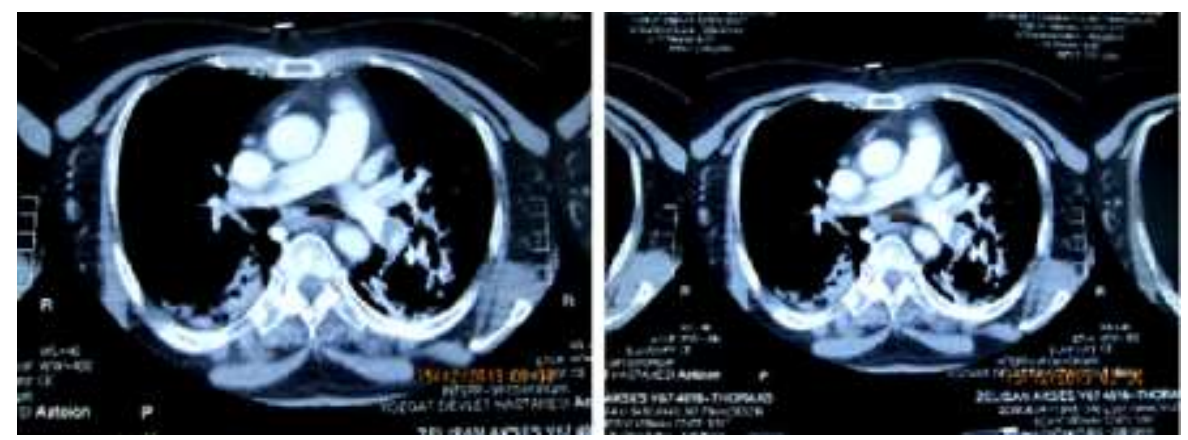

Resim 3. Üçüncü olguya ait BT angiyo.

\section{Olgu 4}

Altmış sekiz yaşında bayan hasta hastane koridorunda senkop geçirme ve kafa travması nedeni ile acil servise getirildi. Acile geldiğinde bilinci konfüze olan hastanın TA 110/70 $\mathrm{mmHg}$ ve Sat $\mathrm{O}_{2} \% 90$ kan şekeri $106 \mathrm{mg} / \mathrm{dL}$ ölçüldü. Acile gelişinden 15 dakika sonra jeneralize kasılmaları oldu. Olası nörolojik nedenleri araştırmak amacıyla yapılan bilgisayarlı beyin tomografisinde patoloji saptanmadi. Transtorasik ekokardiyografide sağ boşlukları genişlemiş ve ana pulmoner arterde trombüs izlendi. acil serviste kardiyopulmonber arrest gelişen hastaya CPR uygulandı, yanıt alınamayan hasta exitus kabul edildi.

\section{Olgu 5}

Altmış dokuz yaşında bayan hasta evinde çarpıntı, halsizlik şikayetlerinin olduğunu ve ayağa kalkınca baygınlık geçirme şikayeti ile getirildi. acil servisimize getirildiğinde bilinci açık koopere-oryante tansiyonu 110/70 mmHg, nabzı 120/dk EKG'sinde atrial fibrilasyon tespit edilen hastanın solunum sayıs1 20/dk idi. Kardiyoloji uzmanı tarafindan yapılan ekokardiyografide hastanın sağ ventrikül ve sağ atriumunda genişleme ve pulmoner hipertansiyon tespit edildi. Laboratuarda D-dimer sonucu $1305 \mathrm{ng} / \mathrm{dL}$ gelen hastaya PE ön tanısı ile BT angiografi çekildi. Pulmoner emboli tanısı konularak tedavi altına alındı ve şifa ile taburcu edildi.
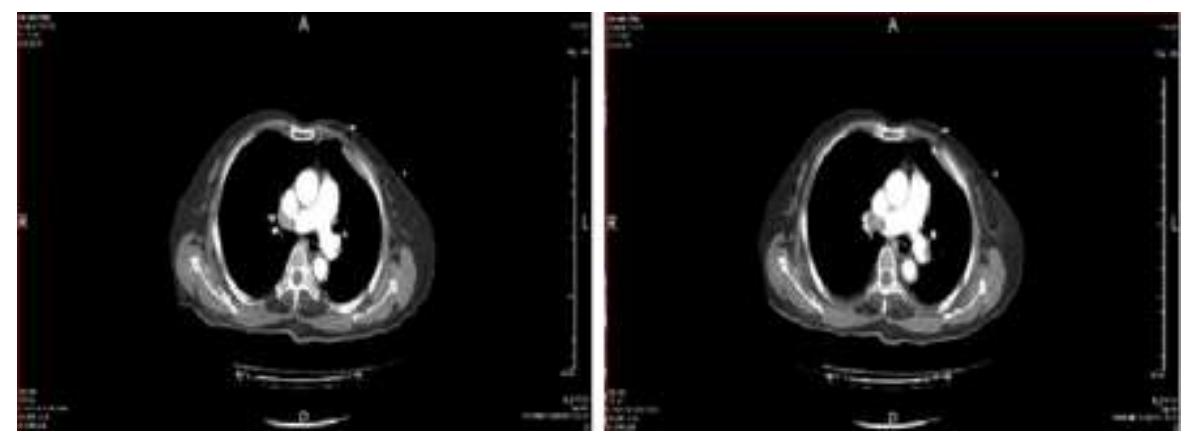

Resim 4. Beşinci olguya ait BT anjiografi.

\section{Tartışma}

Pulmoner emboli vakaları embolinin şiddetine göre çok farklı semptomlarla hastanelere başvurarabilir. Pulmoner emboli şiddetine göre birçok kardiyak ve göğüs hastalığını taklit edebilir ve bu nedenle acil servislerde sık atlanılan hastalıklardandır. Masif PE ise ortostatik hipotansiyon ve senkopa neden olarak serebrovasküler hastalıklarla s1klıkla karışabilmektedir. Özellikle masif pulmoner embolinin ilk 1 saat içinde mortalitesi çok yüksektir ve hastalık hılı bir şekilde tanı konularak tedavinin başlanmasını gerektirmektedir [2, 4].

Masif PE akut sağ ventrikül yetmezliğine bağlı olarak sol ventrikülün etkilenmesi ile oluşan taşikardi, hipotansiyon, serebral perfüzyon bozukluğu ve senkopa yol açar. Burada 
as1l neden sistemik hipotansiyondur. Ana pulmoner arterin tromboemboli ile tıkanmasina bağlı olarak Bezold-Jarisch refleks mekanizması ile hipotansiyon gelişir [5]. Thames ve ark. [1] yaptıkları çalışmada masif PE hastane dışında senkopa neden olduğunda tanı gözden kaçırılabilir demişlerdir. Bunu PE sonrası hipotansiyon kısa bir süre sonra kendiliğinden düzelebilir olmasına bağlamışlardır. Bizim dört olgumuz hastane dışında senkop geçirmişti ve hastaneye geldiklerinde vital olarak stabil durumdalardi. Birinci olgu hasta evde senkop geçirme, ayağa kalkınca baş dönmesi ve yere yığılma şikayetleri ile geldiği için öncelikle serebral kaynaklı vertigo olabileceğini düşünülmüştür. Ancak acil servisimiz içinde ayağa kalkınca ani hipotansiyon gelişmesi ve ardından kısa süreli nöbet ve ardından senkop geçirmesi, $\mathrm{O}_{2}$ satürasyonunun $\% 92$ olması $\left(\mathrm{O}_{2}\right.$ 'siz) ve takibimiz esnasında gögüste ağrı olduğunu belirtmesi, senkop esnasında herhangi bir aritmi olmamas1, bizi pulmoner emboliye yönlendirmiş, bu nedenle hastaya ekokardiyografi yapılarak hastanın tanısı kesinleştirilmiştir. Ekokardiyografide Soga ve ark. [6]'nın belirttiği gibi sağ atriumda serbest yüzen trombüs gözlenmiş̧ir.

İkinci olgu yine evde senkop geçirme şikayeti ile getirildi acil servise geldiğinde bilincinin hala konfüze olması nedeni ile yine öncelikli olarak serebrovasküler hastalık düşünülmüştür. Bu nedenle hastaya beyin $\mathrm{BT}$ çektirilmiş, bu hastada da yine acil serviste takip edilirken yakınları tarafından ayağa kaldırıldığında ortostatik hipotansiyon ve ardından kısa süreli bir nöbet ve ardından senkop geçirdiği gözlemlenmiştir. Hastanın satürasyonunun \%85 olması ve yine aynı şekilde senkop geçirmesi nedenleri ile yapılan ekokardiyografi ile PE tanısı konulmuştur.

Thames ve ark.'nın [1] da belirttiği gibi hastaların hastane dışında senkop geçirme hikayesinin olması acil servis doktorlarına daha çok serebrovasküler hadiseleri düşündürmektedir. Bizim her iki hastamızda da bir nefes darlığı ve taşipne yoktu. Hastalarımızdan daha çok SVO düşündürecek başdönmesi ve bayılma şikayetleri ile acil servise başvurmuşlardı. Daha sonra acil içinde her iki hastanın ani hipotansiyon ve kısa süreli nöbet ve takibinde senkop ve geçirmesi satürasyonlarının düşük olması (\%92 ve \%85) pulmoner emboliyi düşündürmüştür.

Araştırmaya aldığımız dört vakada acil servisimiz içinde önce kısa süreli bir nöbet ve ardından birkaç dakikalık senkop geçirmişlerdir. Meyer MA ve ark. [7] yaptıkları vaka sunumunda da benzer olaylar tarif edilmiştir. Bir vakamızda da Price ve ark'nın [8] bahsettiği gibi Faktör V leiden eksikliği pulmoner emboliye neden olmuştur.

Senkopun ayırıcı tanısında PE'nin düşünülmesi ve fizik muayene ile ayırıcı tanı yapıldıktan sonra yatak başı ekokardiyografi ile de hastaların değerlendirilmesi hem tanı koyma hem de tedaviyi erken başlatma açısından bizim olgularımızda da ilk tercih aracı olmuştur [5]. Tüm olgularımızda tanıya gidilmesinde ekokardiyografi yönlendirici olmuştur. Ancak hastaların istirahatte vital bulguları stabil olduğu için kesin tanısal yöntemler kullanılmıştır.

Pulmoner emboli, Stein ve ark. [4] da belirttiği gibi en sık başvuru bulgusu olan göğüs ağrısı, nefes darlığı ve taşikardi ile belirti vermeyip ortostatik hipotansiyon ve senkop ile belirti verebilir. Senkop; bizim vakalarda da olduğu gibi yapılan bir çalışmada da pulmoner embolisi olan bir vakanın acile tek ve ilk başvuru semptomu olabilir [9]. Senkop PE'nin gözardı edilebilecek bir belirtisi olduğu için acil servise senkop ile başvuran hastaların ayırıcı tanısında PE mutlaka düşünülmelidir [10, 11]. Demircan ve ark. [12]'nın yayınladığı vakada olduğu gibi bizim vakalarımız da senkop şikayeti ile acile başvurmuş, üç vakamız acil içinde kısa süreli hipotansif atak ve nöbet geçirmişlerdir.

Sonuç olarak; vakalardan da görüldüğü gibi masif PE'de olsa hastada istirahatte iken vital bulgularda bozukluk veya ciddi sayllabilecek bir semptom olmayabilir. Ancak ani hipotansiyon ve senkop gelişen hastalarda masif pulmoner olabileceği akılda bulundurulmalıdır. Masif PE olgularında ekokardiyografi kullanımının erken tanı ve tedavi açısından önemi büyüktür. 


\section{Kaynaklar}

1. Morgenthaler TI, Ryu JH. Clinical characteristics of fatal pulmonary embolism in a referral hospital. Mayo Clin Proc 1995; 70: 417-24.

2. Bell WR, Simon TL, de Mets DL. The clinical features of submassive and massive pulmonary emboli. Am J Med 1997; 62: 355-63.

3. Thames MD, Alpert JS, Dalen JE. Syncope in patients with pulmonary embolism. JAMA 1977; 238: 2509-11.

4. Stein PD, Henry JW. Clinical characteristics of patients with acute pulmonary embolism stratified according to their presenting syndromes. Chest 1997; 112: 974-9.

5. 5.Wolfe TR, Allen TL. Syncope as an emergency department presentation of pulmonary embolism. J Emerg Med 1998; 16: 27-31.

6. Soga T, Sato Y, Matsumoto N. Right atrial free-floating thrombus in a patient with massive pulmonary embolism: A case of 'emboli in transit. Int $\mathbf{J}$ Cardiol 2008; 129: 66-8.

7. Meyer MA. Seizure as the presenting sign for massive pulmonary embolism: Case report and review of the literature. Seizure 2009; 18: 76-8.

8. Price DT, Ridker PM. Factor V leiden mutation and the risks for thromboembolic disease; a clinical prospective study. AnnInternMed 1997; 127: 895-903.

9. Jiang AG, Lu HY. Agnogenic massive pulmonary embolism with syncope as initial symptom: A case report and review of the literatüre. Exp Ther Med 2013; 5: 1516-8.

10. Koutkia P, Wachtel TJ. Pulmonary embolism presenting as syncope: Case report and review of the literature. Heart Lung 1999; 28: 342-7.

11. 11. Calvo- Romero JM, Perez- Miranda M, Bureo- Dacal P. Syncope in acute pulmonary embolism. Eur J Emerg Med 2004; 11: 208-9.

12. Demircan A, Aygencel G, and Bildik F. Pulmonary embolism presenting as syncope: A case report. J Med Case Reports 2009; 3: 7440. 